\title{
Daño moral colectivo en el derecho del consumo chileno: Situación actual y proyecciones
}

\section{Collective Moral Damages in Ghilean Consumer Law: Gurrent Situation and Projections}

\author{
FABIÁN GONZÁLEZ CAZORLA*
}

\begin{abstract}
Resumen
El trabajo que presento tiene por objetivo analizar el estado actual del daño moral en los procedimientos de interés colectivo o difuso con motivo de la reforma implementada por la Ley $\mathrm{N}^{\mathrm{o}} 21.081$ a la Ley de protección del consumidor $\mathrm{N}^{\circ}$ 19.496. En primer lugar, se efectúa un examen general del daño moral distinguiendo sus ámbitos de aplicación respecto de intereses individuales y supraindividuales. Posteriormente, se examina la modificación introducida al artículo $51 \mathrm{~N}^{\circ} 2$ de la Ley de protección del consumidor, mediante una reconstrucción conceptual de las hipótesis de procedencia: integridad física, psíquica y la dignidad de los consumidores. El examen se torna crítico por la comprensión que el legislador tiene de los bienes jurídicos que dan lugar a la reparación y de los intereses supraindividuales, llegando a la conclusión que el camino idóneo para hablar de daño moral colectivo en un sentido más depurado se puede construir a través de una adecuada noción de dignidad en el contexto de las relaciones de consumo.
\end{abstract}

Palabras clave: Daño moral colectivo; intereses supraindividuales; daño moral; dignidad; indemnización.

Abstract
The work presented aims to analyze the current state of moral damages in
collective or diffuse procedures resulting from the implementation of Law
No. 21,081 that reforms the Consumer Protection Law No. 19,496. We
start with a general overview of moral damage, differentiating between
individual and collective interests. Later, we assess the modification
introduced by article 51 No. 2 of the Consumer Protection Law, which
conceptually restructured the origin hypothesis: physical and psychological
integrity and the dignity of consumers. The assessment becomes critical
due to the legislator's understanding of legal assets that generate
compensation and collective interests, thus concluding that the suitable
path, in order to talk of collective non-pecuniary damages - in a more
refined sense - can be constructed by an adequate notion of dignity within
the context of consumer relations.

*Universidad Autónoma de Chile, Chile (fabian.gonzalez2@,cloud.uautonoma.cl). Artículo recibido el 28 de septiembre de 2020, aceptado para su publicación el 20 de enero 2021. 
Key words: Collective moral damages; collective interests; moral damages; dignity; compensation.

\section{INTRODUGGIÓN}

El daño moral en el Derecho del consumidor ha tomado una creciente importancia en los últimos años tanto desde un enfoque teórico como práctico. En este último aspecto, la jurisprudencia del consumo, anclándose en la evolución general del daño moral contractual de la jurisprudencia civil, ${ }^{1}$ ha hecho notables esfuerzos para categorizarlo y delimitarlo, al menos en los litigios de interés individual, generando un estado de cosas que hoy parecen encontrar una relativa consolidación.

Gracias al reconocimiento expreso de la procedencia del daño moral en el Derecho del consumo, consagrado en el artículo $3^{\circ}$ letra e) de la Ley 19.496 sobre Protección de los Derechos de los Consumidores, en adelante LPC, la justificación argumentativa para conceder dicha reparación no ha presentado mayores complejidades para los jueces. Aunque, en realidad, el problema real dice relación con el concepto y los mecanismos de delimitación de esta partida indemnizatoria, cuestiones que aun no encuentran una solución ni la dogmática ni en la jurisprudencia.

Respecto del concepto existen distintas acepciones más o menos asentadas en la dogmática civil, ${ }^{2}$ aunque los tribunales tienen una noción amplia de daño moral situándolo en un plano subjetivo que pone acento en el sufrimiento o dolor padecido por el consumidor a causa del incumplimiento del proveedor. Ciertamente, esa postura proviene de las

\footnotetext{
${ }^{1}$ Como ejemplos de las sentencias relevantes en materia de daño moral contractual que cambiaron el paradigma puede verse: Rafart con Banco de Chile (1994) y Ruiz con Laboratorio Biológico y otros (2004). El considerando $17^{\circ}$ señala lo siguiente: "El citado artículo 1556 del Código Civil, como ya quedó establecido precedentemente, no limita la reparación en materia contractual al daño emergente y lucro cesante, desde luego no excluye al daño moral."

2 Por ejemplo, Alessandri define daño moral como: "dolor, pesar o molestia que sufre una persona en su sensibilidad física o en sus sentimientos, creencias o afectos”. Alessandri Rodríguez (1943), p. 220. A juicio del profesor Enrique Barros el daño moral entraña diversos supuestos de aplicación que no tienen una expresión nítida, de hecho, indica que "Lo cierto es que el término 'daño moral' tiende a oscurecer la pregunta por el tipo de daños a que se hace referencia. En efecto, la idea de un daño 'moral' alude correctamente a la lesión de bienes como el honor y la privacidad, pero solo imperfectamente expresa otros daños no patrimoniales, como, por ejemplo, el dolor físico, la angustia psicológica o la pérdida de oportunidades para disfrutar de una buena vida” BARRos BouRIE (2006) p. 231. Del mismo modo, la profesora Carmen Domínguez señala que "estamos con aquellos que conciben el daño moral del modo más amplio posible, incluyendo allí todo daño a la persona en sí misma -física o psíquica-, como todo atentado contra sus intereses extrapatrimoniales. Comprende pues el daño moral todo menoscabo del cuerpo humano, considerado como un valor en sí y con independencia de sus alcances patrimoniales." Domínguez HidAlgo (2000), p. 83. En España pueden mencionarse, por ejemplo, MARTIN-CASALS et al. (2003,) p. 858, señalan que "daño moral es el perjuicio que experimenta una persona y que no afecta a su patrimonio, ni a sus ingresos, ni puede cuantificarse económicamente con referencia a un valor de mercado"; DiEz-PICAZO sostiene que "nos inclinamos por entender que el denominado daño moral debe reducirse al sufrimiento o perturbación de carácter psicofísico en el ámbito de la persona, sin proceder al respecto a concepciones extensivas, en las que la indemnización carece de justificación. Aun concebido en los estrictos términos que se acaban de esbozar, no todo sufrimiento psicofísico engendra un daño moral indemnizable, sino (...), aquel que es consecuencia de lesiones de derechos de la personalidad". Véase DiEzPiCAZO (1999), p. 328.
} 
interpretaciones que efectúan los tribunales ejerciendo la jurisdicción ordinaria, agudizando la noción subjetiva cuando se trata de la infracción a derechos de los consumidores. ${ }^{3}$

Ahora bien, teniendo en cuenta lo anterior, el propósito de este trabajo consiste en analizar el denominado daño moral colectivo que ha sido implementado con la reforma de la LPG mediante la Ley 21.081, norma que reconoce la procedencia de esta clase de reparación en los procedimientos de interés colectivo y difuso de acuerdo con el nuevo artículo $51 \mathrm{~N}^{\circ} 2$.

Bajo este escenario se identifican algunos problemas que incidirían directamente en la comprensión de esta institución, respecto de los cuales trataremos de hacernos cargo con mayor o menor intensidad. En primer lugar, se plantea que existen problemas relativos a la efectiva indemnización del daño moral (y por cierto patrimonial) con ocasión de procedimientos de interés difuso, puesto que los principios que inspiran la responsabilidad civil llevan a excluir la reparación (en sentido puro) a grupos indeterminados. La segunda cuestión dice relación con la forma en que el legislador de consumo chileno entiende el daño moral colectivo: a primera vista se trataría de una categoría híbrida que no responde al concepto técnico de un daño supraindividual, sino a una mezcla entre intereses individuales y supraindividuales, atendido a las hipótesis de procedencia.

\section{EL DAÑO MORAL GOLEGTIVO}

El daño moral colectivo constituye una categoría dogmática especial de la institución general del daño moral que surge en forma autónoma desde una doble perspectiva. La primera como una diferenciación entre los daños que pueden padecer las personas en un plano puramente individual o particular, respecto de otros que suelen estar vinculados a la colectividad o un grupo más o menos determinados de individuos. En segundo lugar, el daño moral colectivo se erige como respuesta al notable cambio que han tenido las relaciones de consumo en el ámbito supraindividual, en donde uno o más proveedores entrelazan su actividad con un número importante de personas, consideradas como un todo, a quienes les afectan las consecuencias derivadas de la infracción a sus derechos o intereses. Sin embargo, la pregunta que naturalmente surge es cómo debe ser entendido el daño moral colectivo.

\section{1 ¿Qué es el daño moral colectivo?}

Inicialmente podemos decir que no existe en la actualidad una definición completa o absoluta de daño moral en el contexto de las relaciones de consumo y menos de daño moral colectivo. Si bien se puede recurrir a la jurisprudencia del consumo para tener una noción

\footnotetext{
${ }^{3}$ Muñoz con Administradora de Supermercado Express Limitada (2012), considerando 9': "Que, habiéndose acreditado en autos, que el proveedor incurrió en infracción al artículo 23 de la citada ley, producto de haber obrado con negligencia en la prestación del servicio otorgado al consumidor, actuación que obviamente causó un daño moral a ésta, el cual está constituidos por las molestias y sufrimiento que le ha ocasionado la pérdida de su vehículo (...)". La misma idea se repite en una sentencia de la Corte de Apelaciones de Concepción, que señala que: "el daño moral está representado por las incomodidades y molestias, frustración y sensación de engaño que ha sentido la compradora al percatarse que el producto que adquirió, el cual ella creía nuevo, no lo era (...)". Véase Fredes con Multitienda Corona S.A. (2013), considerando $5^{\circ}$.
} 
respecto de lo que se discute en la práctica judicial en los litigios individuales, lo cierto es que la dogmática civil ha realizado algunos esfuerzos para delinearlo y establecer algunos parámetros conceptuales. ${ }^{4}$

Uno de los ejes centrales de dicha conceptuación está puesto en la noción de interés. Así, y como es sabido, el interés comprometido de la víctima es una categoría independiente del bien jurídico lesionado. En efecto, se puede producir un daño a un interés extrapatrimonial de la persona, al margen de la naturaleza específica del bien, cosa o derecho vulnerado, es decir, con independencia de si este es de carácter patrimonial o extrapatrimonial. ${ }^{5}$

En el caso del daño moral colectivo debe afirmarse, en primer lugar, que este se sitúa en el plano de los intereses supraindividuales y como tal su configuración no puede depender de la repercusión personal que se produzca a los miembros que componen el grupo lesionado. En otras palabras, la afectación individual (de la naturaleza que sea) que el hecho ilícito genera en las personas es un factor que no necesariamente está ligado al concepto normativo de daño moral colectivo. En consecuencia, puede haber un daño colectivo sin que haya dolor o sufrimiento de parte de las personas que componen tal colectividad. ${ }^{6}$ Como también pueden concurrir el daño colectivo con uno de naturaleza individual, sin que por ello pierdan cada uno su respectiva independencia.

De esta forma, al ser el daño colectivo (moral) un perjuicio autónomo respecto de las repercusiones individuales que pueden recibir los miembros de esa colectividad, este tiende a separarse no solo en una cuestión grado, sino desde una perspectiva cualitativa. Tradicionalmente el daño moral se ha ligado íntimamente a la persona, a su ser mismo y a sus facultades más esenciales, lo que ha significado que se le otorgue un carácter personalísimo. $^{7}$ Sin embargo, el daño moral colectivo se aleja en cierta medida de aquella característica porque su ámbito normativo de aplicación es diferente, ya no se trata de la angustia, el dolor, sufrimiento, molestia o zozobra que afecta al individuo, ni tampoco que dicho dolor sea experimentado por muchas personas, sino que hay, en realidad, una lesión a

\footnotetext{
${ }^{4}$ La doctrina ha definido el daño moral en el contexto de las relaciones de consumo como: “(...) un perjuicio o lesión que afecta a un interés moral de la persona, que comprende no solamente su integridad física, sino también psíquica, y abarca, por esa misma razón, una serie de elementos no corporales sino de afectación espiritual y de disfrute de la vida en un contexto determinado". Véase GONZÁLEZ CAZORLA (2019), p. 142.

${ }^{5}$ En este sentido, Aedo señala "[e]l daño se configurará, por tanto, cuando se ha afectado un interés de la víctima, con independencia del menoscabo de la cosa, bien o derecho y con independencia de su carácter, patrimonial o extrapatrimonial. De ahí se sigue, como hemos visto, que la lesión a un bien patrimonial puede generar afectación de intereses tanto patrimoniales como extrapatrimoniales y viceversa". AEDO BARRENA (2019), pp. 169-170. En el mismo sentido Domínguez Hidalgo (2000), p. 66.

${ }^{6}$ En un sentido similar Cavalieri señala "puede haber ofensa a la dignidad de la persona humana sin dolor, vejación o sufrimiento, así como puede haber dolor, vejación y sufrimiento sin violación de la dignidad". Cavalieri Filho (2012), p. 89.

${ }^{7}$ Pueden consultarse los siguientes fallos que se fundan en el carácter personalísimo del daño moral para rechazar la transmisibilidad del mismo a los herederos del causante. Así, por ejemplo, Huentemil y otros con Agro Inversiones (2007); Cortez y otros con Cooperativa de Servicios Educacionales Windsor School Ltda. (2010); Cuevas con Distribuidoras de Industrias Nacionales S.A., (2011); Quezada con Colmenares Werner Limitada (2016); Quezada con Colmenares Werner Limitada (2016), sentencia de la Corte Suprema, en esta última se accede a la transmisibilidad de la acción por daño moral.
} 
un interés grupal, ${ }^{8}$ que se materializa con la afectación de derechos de la personalidad ${ }^{9}$ o la calidad de vida, pero de la colectividad toda. ${ }^{10}$

Por cierto, esto no es una cuestión pacífica, puesto que no resulta del todo claro quien debe ser el sujeto vulnerado para solicitar la compensación por daño moral colectivo. Algunos piensan que la afectación individual de las personas dentro de un grupo legitimaría una acción colectiva, ${ }^{11}$ otros opinan que el daño moral colectivo ni siquiera resulta procedente como categoría dogmática por la noción misma de daño moral y su naturaleza, ${ }^{12}$ y porque su carácter subjetivo resulta incompatible con una acción colectiva. ${ }^{13}$ Sin embargo, aquellas críticas se construyen sobre la base de la noción individual y subjetiva de daño moral, y no desde el plano de los intereses supraindividuales, además, no consideran que este tipo de lesión tiene diversos ámbitos de aplicación, algunos incluso con cierto matiz objetivo como la violación de un derecho de la personalidad (imagen, honra, salud, etc.). Seguidamente, el concepto mismo de daño moral colectivo deja fuera las perturbaciones individuales y, en su lugar, consiste en la afectación de un bien superior pero común a todos los sujetos involucrados, como lo sería, por ejemplo, la afectación de la dignidad. Ahora bien, el grado de afectación y las condiciones de procedencia es otro tema, pero es importante distinguir que los ámbitos de aplicación del daño moral son normativamente diferentes y que no cabe confundir una noción estrictamente individual y subjetiva con una en donde dicho plano individual no es un factor determinante. Por este motivo, yo me inclino más por separar los planos de afectación y situar al daño moral colectivo como una lesión a un interés grupal.

Asumir esta última noción tiende a otorgar al daño moral colectivo un carácter más objetivo y reconocer el valor que hoy en día tiene la "sociedad de masas". La época en donde el individualismo liberal era el centro de atención para el desarrollo y protección del ser

\footnotetext{
${ }^{8}$ En este sentido Aldo Molinari señala que “(...) el interés afectado no es individual sino que es de carácter colectivo y, en nuestra opinión, solo en este caso debiera hablarse de "daños colectivos". En este sentido, el daño colectivo no se determina por el número de personas involucradas por el evento dañoso, sino por la naturaleza del interés afectado, el que corresponde a un interés grupal o colectivo". Véase MOLINARI VALDÉs (2018), p. 521.

9 Medeiros Bahia y Gomes Medeiros (2019), p. 40. En Chile la profesora Carmen Domínguez ha comentado la importancia que tiene la concepción de los derechos de la personalidad y los mecanismos de tutela. Estos derechos, como expresión de la persona, pueden y deben ser tutelados de una manera amplia, por ejemplo, a través de una acción indemnizatoria. Véase Domínguez HidALGO (2019), pp. 87-88.
}

10 Pizarro Wilson (2013), p. 219.

${ }^{11}$ En este sentido, se ha señalado que "[n]o parece probable que el ordenamiento jurídico quiera que todas las desolaciones, sufrimientos o disgustos que sufran las personas son ilegítimas, y que siempre deben ser compensadas o satisfechas, ya que ello conllevaría a los sujetos a la más absoluta inactividad para evitar cualquier frustración en los terceros con los que se relacionaren. Pero habrá casos en que el intérprete puede advertir la posibilidad cierta y no exagerada de solucionar por la vía de una indemnización en un juicio colectivo la real afectación a intereses extrapatrimoniales.” LORENZINI BARRÍA (2015), pp. 441-442.

12 Munita Marambio (2019), p. 225. El autor señala "La pregunta que cabe formularse, entonces, es la que sigue: ¿resulta dogmáticamente sostenible la interposición de acciones colectivas que persiguen la reparación del daño moral de los involucrados bajo la órbita de la misma?, o, en otras palabras, ¿la reforma legal es coherente respecto de las consideraciones que sobre el daño moral hemos hecho referencia más arriba? Creemos que no."

${ }^{13}$ Munita Marambio (2019), p. 225. En un sentido similar Molinari ValdÉs (2018), p. 516. 
humano ha dado paso a un nuevo paradigma que privilegia ciertos bienes comunes como parte integrante de su vida. Basta nombrar el derecho a vivir en un medio ambiente libre de contaminación o el respeto de intereses colectivos como el de los indígenas, trabajadores o consumidores, para evidenciar que hoy el derecho debe dar respuesta no solo a necesidades individuales sino también colectivas. Ciertamente, esas respuestas se incardinan mediante la protección de tales grupos. En el caso del daño moral que estos pueden padecer, es indispensable separar los planos o ámbito de aplicación según he dado cuenta en los párrafos anteriores; y se ha tratado de buscar esa separación mediante la categoría de derechos de la personalidad que, si bien se proyectan desde el individuo, su materialización se produce en contexto de convivencia colectiva o social, separándose en última instancia, estos, para tener autonomía y vida propia. En general, la vulneración del grupo se materializará en la afectación de su dignidad, calidad de vida o cualquier otro atributo derivado de derechos o bienes de la personalidad.

\subsection{Daño moral colectivo y los beneficiarios de la sentencia condenatoria: ¿Problemas?}

Hasta ahora he dicho que el daño moral colectivo se sitúa en el plano de los intereses supraindividuales, es decir que afectan a un grupo y no a una persona en particular. Si esto es correcto, entonces la conclusión obvia sería que, de obtenerse una sentencia condenatoria en contra del proveedor demandado - producto de una acción indemnizatoria de clase-, sea compensado el grupo lesionado, algo así como compensar al colectivo compuesto por muchas personas. Sin embargo, aquello que constituye una aspiración legítima de la protección de un interés global, puede perjudicar en términos prácticos a quienes realmente resultan afectados por el hecho ilícito.

Mi premisa entonces es la siguiente, el daño moral colectivo se genera por la afectación de un interés grupal. Sin embargo, cuando los efectos de una eventual sentencia condenatoria quisieran hacerse valer, los beneficiarios no pueden ser sino las personas (determinadas o determinables) que componen ese grupo lesionado. Pues bien, si se busca un objetivo eminentemente reparatorio fundado en los principios de la responsabilidad civil, no puede ser de otro modo. Ahora, si la finalidad no es la indemnización sino la consecución de otros fines, diversos a la efectiva reparación, pueden perfectamente operar mecanismos de distribución del monto obtenido, como por ejemplo entregando dineros a entidades benéficas o que cumplan funciones de ayuda a los consumidores, rebaja de precios u otras alternativas.

Esto nos lleva a replantearnos la posibilidad de que, bajo el amparo de la reforma introducida a la LPG, puedan ser efectivamente indemnizados los consumidores afectados a título de daño moral colectivo, incluso a título de daño patrimonial.

\subsection{1 ¿Es posible indemnizar el daño moral colectivo a los consumidores?}

Uno de los cuestionamientos que cabe formular respecto de la procedencia y aplicación del daño moral colectivo dice relación con las personas legitimadas y beneficiadas de esta acción. En este sentido, cobra relevancia la reciente modificación introducida a la 
LPG mediante la Ley 21.081 en torno a que la indemnización de perjuicios puede ser solicitada no solamente por quienes sean sujetos determinados al estar unidos con el proveedor por un vínculo contractual, sino también aquellos que tienen el carácter de indeterminados a la luz del artículo 50 inciso $5^{\circ} \mathrm{LPG}$.

Como se puede observar, aunque no de forma expresa, la reforma abriría la posibilidad de que sujetos indeterminados (interés difuso) puedan demandar indemnización de perjuicios amparándose en el procedimiento de interés colectivo dispuesto por la ley, ${ }^{14}$ especialmente el daño moral, lo que provocaría algunas distorsiones si efectúa una lectura detenida.

En efecto, la cuestión es mucho más profunda de lo que se cree, puesto que la discusión sobre la reparación de sujetos indeterminados en procesos colectivos es un tema que, si bien escapa a los propósitos de este trabajo, puede igualmente ofrecernos un terreno fértil para plantear algunos cuestionamientos sobre el daño moral indemnizable en dicha sede.

Como primera aproximación debemos señalar que la reparación del daño moral en procedimientos de interés colectivo es plenamente procedente por disposición expresa de la ley (art. $51 \mathrm{~N}^{\mathrm{o}} 2 \mathrm{LPC}$ ). Sin embargo, esto no es tan claro respecto de los intereses difusos porque no existe certeza de quienes habrían sufrido el daño. Por otra parte, de la lectura de la LPG se extrae que el sistema que se ha adoptado para la reparación de daños colectivos es opt-out en relación con la sentencia que declara la indemnización en favor de los consumidores (efecto erga omnes, art. $54 \mathrm{LPG}$ ), pero al mismo tiempo opera como un modelo opt-in, al exigir la acreditación de los consumidores afectados de su condición de miembro de un grupo lesionado (art. 54 D LPG). ${ }^{15}$

La duda que surge, entonces, es qué ocurre con los consumidores que no pueden ser identificados y que, por consiguiente, no harán valer sus derechos de acuerdo al artículo 54 D LPG. Esto lleva a pensar que la indemnización en razón del daño moral declarado por el juez jamás llegaría a los bolsillos de los consumidores abstractamente afectados, bien porque no podrán acreditar su condición de pertenencia a un grupo, bien porque simplemente no acudirán a hacer valer sus derechos y dejarán el remanente señalado en el artículo $53 \mathrm{C}$ de dicha norma.

Adicionalmente, existe un fuerte cuestionamiento acerca del verdadero carácter indemnizatorio de la LPC a consumidores indeterminados. Como dije anteriormente, la reforma parece haber abierto un espacio para la reparación a dichos sujetos, sin embargo la lógica que está detrás de esta especie de compensación no parece situarse en el campo de la responsabilidad civil como la conocemos, porque elementos como la personalidad y certidumbre del daño, ${ }^{16}$ que no están presentes cuando se litiga en favor de intereses difusos, llevan a pensar que la estructura y esencia de la protección de esos derechos descansa más bien en un carácter punitivo o de public enforcement, en el que importa, más allá de la

\footnotetext{
${ }^{14}$ En este sentido De la MaZa GaZmuri (2020), p. 788.

${ }^{15}$ Rodríguez Diez y Zavala AchurRa (2019), p. 171

${ }^{16}$ Rodríguez Diez y Zavala AchurRa (2019), p. 153 y 166.
} 
compensación a las víctimas, que el autor de un ilícito (especialmente en materias de libre competencia) ${ }^{17}$ sea sancionado y disuadido de su mal comportamiento en el futuro. ${ }^{18}$ Tal es el papel que han desempeñado los ordenamientos europeos de derecho continental, en el que los procesos colectivos con carácter indemnizatorio solo están previstos para quienes acrediten su condición de miembro de grupo, excluyéndose a sujetos indeterminados de una indemnización, con la que resultaría verdaderamente un efecto disuasivo para el proveedor infractor en lugar de un genuino efecto reparatorio. ${ }^{19}$

Esos modelos de compensación a sujetos indeterminados son conocidos como cy-près ofluid recovery, ${ }^{20}$ doctrina que, si bien puede remontarse al Derecho romano, ${ }^{21}$ tiene un origen más articulado en el common law para reasignar el destino de los bienes o efectos patrimoniales de un testador o donante a entidades benéficas, que por distintas razones no pueden cumplir la voluntad del instituyente, y se prefiere buscar una alternativa semejante, por eso se utiliza la expresión "cy pres comme ce possible" (tan próximo como sea posible).22

La cuestión entonces estriba en si los daños morales difusos pueden ser considerados como indemnizables bajo la estructura y lógica de la responsabilidad civil, o bien pueden ser objeto de mecanismos alternativos de reparación de acuerdo a la legislación chilena. A este respecto, cobra relevancia una circular del Servicio Nacional del Consumidor (Sernac) del 6 de noviembre de 2020 en virtud del cual sostiene que es posible indemnizar a sujetos indeterminados aplicando la doctrina del cy pres ofluid recovery conforme a la actual legislación. Para ello utiliza una serie de criterios que irían en esa misma dirección ${ }^{23}$ (tales como: a) primacía de la reparación directa; b) proximidad; c) no afectación del artículo 11 bis y; d) carácter excepcional y subsidiario).

\footnotetext{
17 Sobre la compensación de daños a los consumidores puede verse también HeRnández PAULSEN (2018), quien sostiene, a la fecha de publicación de su trabajo, que de haber existido una norma como el actual artículo $51 \mathrm{~N}^{\circ} 2$ LPC, se habría podido indemnizar el daño moral colectivo a los consumidores producto de conductas anticompetitivas de los proveedores, como la colusión. Así, el autor señala "(...) con la entrada en vigencia de la mencionada modificación, los consumidores podrían aspirar a indemnización por los daños extrapatrimoniales ocasionados por la colusión, $v$. gr., por atentados contra su integridad física o psíquica o su dignidad. A modo de ejemplo - pensando en el "Caso farmacias"-, de haber existido una norma como la referida al momento de originarse los hechos que lo motivaron, los consumidores que no pudieron adquirir remedios para tratar sus enfermedades, podrían haber obtenido resarcimiento del daño extrapatrimonial por la agravación de sus patologías o por los nuevos menoscabos a la salud padecidos como consecuencia directa de la colusión.” Hernández PAULSEN (2018), p. 113.

18 En este sentido Hernández Paulsen y Tapia Rodríguez (2019), p. 7.

19 A este respecto véase la Directiva 2014/104/UE del Parlamento Europeo y del Consejo de 26 de noviembre de 2014, considerando 13.

20 Aunque suelen utilizarse como términos idénticos, lo cierto es que entre ellos existe una diferencia de aplicación. Mientras el que el Fluid recovery "(...) implicaría una reparación global, liquidación y ejecución fluida, para toda la clase [afectada]", el cy pres doctrine tiene un sentido más restringido que alude a "una solución próxima, cercana o relacionada en cuanto sea posible con la clase afectada”. Véase ToLOSA (2017), p. 79.

${ }^{21}$ Rodríguez Diez y Zavala AchurRa (2019), p. 155.

22 Tolosa (2017) p. 78. También REDISH et al. (2010), p. 624 señalan: "The term "cy pres" derives from the French expression "cy pres comme possible", which means "as near as possible".

${ }^{23}$ Páginas 11 a 14 de la Circular interpretativa.
} 
Sin embargo, dicha circular tiene algunos elementos que a mi juicio parecen situarse en un plano distinto al de la responsabilidad civil y, por ende, alejado de una verdadera función reparatoria de los intereses difusos. Primero, porque considera que el cy pres es una doctrina que, además de la reparación, sirve para sancionar al proveedor por su incumplimiento, otorgándole a la indemnización una función punitiva. En segundo lugar, el pretendido cy pres que podría tener lugar no da margen al juez para el determinar el destino de los fondos no reclamados, puesto que por ley estos van directamente al fondo concursable del artículo 11 bis LPG. Por último, el mismo principio de reparación integral excluiría que consumidores no determinados queden indemne, puesto que los fondos no irían en su directo beneficio, dejando a muchas personas sin ninguna compensación.

Por estos motivos, resulta sugerente abandonar la idea de una efectiva indemnización a sujetos indeterminados $\mathrm{y}$, tal como lo señala la doctrina, cambiar el vocabulario de la responsabilidad civil para arribar a otro modelo de compensación indirecto, ${ }^{24}$ precisamente el cy pres ofluid recovery, pero con una estructura distinta en donde el juez tenga la posibilidad de asignar los montos de dinero a un fin lo más cercano posible a la reparación que hubiesen recibido los consumidores.

Nada más lejano a una efectiva compensación es que los montos que quedan como remanentes sean destinados a un fondo concursable. Si en realidad se busca una reparación, el cy pres debe ser replanteado para nuestro ordenamiento jurídico, de lo contrario solo cumpliría una función punitiva y disuasiva del proveedor infractor, que no es esencialmente lo que se busca tras una demanda en el que los intereses de miles de consumidores están comprometidos.

De ahí que el daño moral colectivo, implementado por la reforma, sea más bien una institución que responde de mejor manera cuando los consumidores son determinados y ciertos, respecto de aquellos que son indeterminados y dejan sin respuesta a los elementos de certidumbre y atribución personal del daño, propios de la responsabilidad civil.

\section{INGORPORAGIÓN DEL DAÑO MORAL GOLEGTIVO A TRAVÉS DE LA LEY 21.081}

La Ley 21.081, publicada el 13 de septiembre de 2018 y cuya vigencia, de acuerdo con el artículo primero transitorio de la misma norma, se hizo efectiva seis meses después, esto es en marzo de 2019, introdujo una serie de modificaciones a la LPC, siendo las que importan para este trabajo aquellas referidas a la reparación del daño moral en los procedimientos de interés colectivo o difuso, algo que estaba expresamente prohibido por el legislador antes de la reforma.

A diferencia de Chile, otros países de la región ya habían reconocido la procedencia de la indemnización del daño moral en los procedimientos de interés colectivo. Por ejemplo, Brasil, en la década de los 80 reguló lo que denominó “acción civil pública" mediante la Ley 7.347 del 24 de julio de 1985. Esta norma permite demandar la responsabilidad por daños

\footnotetext{
${ }^{24}$ De la MAZa GaZmuri (2020), pp. 795-796.
} 
causados al medio ambiente, al consumidor y a los bienes de valor artístico, estético, histórico, turístico o paisajístico. ${ }^{25}$

Sin embargo, la regulación más amplia y desarrollada de las acciones colectivas es la que se introdujo mediante la promulgación del Código de Defensa del Consumidor mediante Ley 8.078 del 1990. En el artículo $6^{\circ}$ párrafo VI indica que uno de los derechos básicos del consumidor consiste en: "La efectiva prevención y reparación de daños patrimoniales y morales, individuales, colectivos y difusos. " ${ }^{26}$ Asimismo, también se observan avances en la materia en países como Colombia ${ }^{27}$ o Argentina, ${ }^{28}$ aunque en este último caso con algunos matices.

Ahora bien, en el caso chileno el texto de la norma es elocuente en el sentido de ofrecer una serie de reglas que intentan modelar la pretensión indemnizatoria de los consumidores en los procedimientos de interés colectivo o difuso. A este respecto, conviene citar lo que señala el nuevo artículo $51 \mathrm{~N}^{\circ} 2$ LPG para comprender de mejor forma la institución:

Sin perjuicio de los requisitos generales de la demanda, en lo que respecta a las peticiones relativas a perjuicios, bastará señalar el daño sufrido y solicitar la indemnización que el juez determine, conforme al mérito del proceso, la que deberá ser la misma para todos los consumidores que se encuentren en igual situación. Con este fin, el juez procederá de acuerdo a lo dispuesto en el artículo $53 \mathrm{~A}$. No habrá lugar a la reserva prevista en el inciso segundo del artículo 173 del Código de Procedimiento Civil.

Las indemnizaciones que se determinen en este procedimiento podrán extenderse al daño moral siempre que se haya afectado la integridad física o síquica o la dignidad de los consumidores. Si los hechos invocados han provocado dicha afectación, será un

25 Ovalle Favela (2013), p. 154.

${ }^{26}$ Para lograr tal fin se propuso la distinción conceptual entre ambos tipos de intereses, algo que efectúa en el artículo 81 de este cuerpo normativo, indicando que intereses o derechos difusos son "los transindividuales, de naturaleza indivisible, que sea titulares personas indeterminadas y ligadas por circunstancias de hecho" (Parte I, párrafo único). Por su parte, los intereses o derechos colectivos son "los transindividuales de naturaleza indivisible, de que sea titular un grupo, categoría o clase de personas ligadas entre sí o con la parte contraria por una relación jurídica base" (Parte II, párrafo único).

${ }^{27}$ La regulación colombiana sobre el daño moral colectivo que pudieren sufrir los consumidores es más bien indirecta. Dicho de otra forma, este mecanismo de tutela se materializa a través de la introducción de la responsabilidad por productos o servicios defectuosos y el reconocimiento general de la protección de los consumidores contra riesgos para su salud y seguridad de acuerdo al artículo 1.1 de la Ley 1.480 de 2011. Así, los productos o servicios que afecten a la integridad física o salud de los consumidores podrán legitimar en buena forma una demanda colectiva en contra del causante del daño. Desde luego, los rubros que estarían cubiertos son de índole moral por la naturaleza de los bienes lesionados. Debe eso sí, efectuarse la prevención que en el Derecho colombiano se distinguen los derechos e intereses colectivos (incluidos en estos los difusos) y los derechos e intereses de grupo, y que estos últimos servirían para proteger los intereses sectoriales como el de los consumidores. En este sentido OVAlle FAVELA (2013), pp. 161-162.

${ }^{28}$ Mediante Ley 24.240 del año 1993, consagró la denominada Ley de Defensa del Consumidor (LDG). En esta norma se contempla la protección de los intereses colectivos en el artículo 52, pero nada se dice sobre el daño moral colectivo y, aunque la doctrina argentina se encuentra dividida, algunos piensan que igualmente podría pedirse la reparación de este tipo de daño en dicho procedimiento. Así, SÁEnZ (2014), p. 140. 
hecho sustancial, pertinente y controvertido en la resolución que reciba la causa a prueba.

Con el objeto de facilitar el acceso a la indemnización por daño moral en este procedimiento, el Servicio pondrá a disposición de los consumidores potencialmente afectados un sistema de registro rápido y expedito, que les permita acogerse al mecanismo de determinación de los mínimos comunes reglamentados en los párrafos siguientes. Lo anterior, sin perjuicio del ejercicio del derecho consagrado en el párrafo $4^{\circ}$.

En la determinación del daño moral sufrido por los consumidores, el juez podrá establecer un monto mínimo común, para lo cual, de oficio o a petición de parte, podrá ordenar un peritaje, sin perjuicio de poder considerarse otros medios de prueba. Dicho peritaje será de cargo del infractor en caso de haberse establecido su responsabilidad. De no ser así, se estará a lo dispuesto en los incisos segundo y tercero del artículo 411 del Código de Procedimiento Civil.

En caso de que se estableciere un monto mínimo común, aquellos consumidores que consideren que su afectación supera dicho monto mínimo podrán perseguir la diferencia en un juicio posterior que tendrá como único objeto dicha determinación, sin que pueda discutirse en él la procedencia de la indemnización.

Este procedimiento se llevará a cabo ante el mismo tribunal que conoció de la causa principal, de acuerdo a las normas del procedimiento sumario, en el que no será procedente la reconvención; o ante el juzgado de policía local competente de acuerdo a las reglas generales, a elección del consumidor.

El proveedor podrá efectuar una propuesta de indemnización o reparación del daño moral, la que, de conformidad a los párrafos anteriores, considerará un monto mínimo común para todos los consumidores afectados. Dicha propuesta podrá diferenciar por grupos o subgrupos de consumidores, en su caso, y podrá realizarse durante todo el juicio.

La cita del texto normativo deja entrever algunas reflexiones importantes que inciden en la forma en que se debe reparar el daño moral colectivo. Por esta razón, nos referiremos a algunas ideas con un tono crítico, pero también con un enfoque prospectivo.

\section{1 ¿Cómo entiende la LPG el daño moral colectivo?}

De la lectura del texto se advierte que la reparación del daño moral, en los procedimientos de interés colectivo o difuso, tiene lugar cuando se afecta la integridad física, psíquica o la dignidad de los consumidores (art. $51 \mathrm{~N}^{\mathrm{o}} 2$ párrafo 2 LPG). Sin embargo, uno de los puntos críticos de la regulación es que se asocia el perjuicio a un conjunto de daños individuales que, por circunstancias de hecho y meramente contingentes, parecieran ser la suma de afectaciones individuales o particulares en lugar de la lesión a un interés grupal. En otras palabras, lo que ha hecho el legislador mediante la introducción de esta categoría no es pura y simplemente reconocer la procedencia del daño moral colectivo, sino un daño 
individual homogéneo que es sufrido por un número determinado o determinable de personas. $^{29}$

Además, las primeras dos hipótesis de procedencia me presentan algunas interrogantes importantes, puesto que, fuera de los casos de un alimento expendido por un proveedor en mal estado o medicamentos que no son seguros para la población, cuesta pensar en otras circunstancias que hagan posible una afectación masiva de la integridad física de las personas.

Algo similar ocurre con la integridad psíquica. Dejando fuera las perturbaciones y molestias propias de todo incumplimiento o infracción de algún derecho, ${ }^{30}$ cuesta imaginar cómo un proveedor puede vulnerar seriamente este bien jurídico de muchos consumidores, además, surge la pregunta acerca de cómo se pretende llevar adelante un litigio en que quede demostrado que los consumidores que adhieren a la acción colectiva han sufrido ese daño.

$\mathrm{Al}$ respecto, es importante recordar que el daño colectivo consiste en una lesión a un bien o interés colectivo, cuyo ejercicio no es exclusivo por una persona, sino que es indivisible. ${ }^{31}$ De ahí que la crítica se extienda a un segundo punto. Este se refiere a que el daño moral colectivo consagrado por el legislador se hace dependiente de los padecimientos que tengan los consumidores en un plano individual, como lo es en la afectación de su integridad física y psíquica. En estos casos no se observa con claridad la separación que habría entre un daño puramente individual, aunque sea padecido por muchos, respecto de un daño a un bien colectivo.

Algo ya había anticipado al respecto, el daño moral colectivo en un sentido técnico, no puede depender de la sensación individual que tengan las personas sobre la lesión a un interés que beneficia a muchos. Sin embargo, el legislador chileno no hace sino confundir los planos de actuación del daño moral, el individual y el colectivo, en circunstancias que se trata de ámbitos de protección normativamente diferentes.

Por lo anterior, es probable que esta concepción del daño moral -ahora como daño moral colectivo- sea resultado de la influencia de la doctrina y jurisprudencia tradicional que lo sitúa en un plano estrictamente subjetivo, como sufrimiento o dolor, o de afectación de alguno de los bienes esenciales del ser humano, como la integridad física. Pero, por otro lado, creo que el nuevo articulado nos entrega algunas luces técnicamente más depuradas que se acercan al concepto de daño moral colectivo. Estas se refieren a la afectación de la dignidad como categoría normativa e hipótesis de procedencia.

\footnotetext{
${ }^{29}$ En el mismo sentido, BARRIENTOS CAMUs (2017), p. 23. La autora señala “(...) ahora conviene mostrar las nuevas directrices que contempla el texto aprobado relacionadas con la indemnización de perjuicios. La primera, es el establecimiento de 'daños morales colectivos' en el artículo $51 \mathrm{~N}^{\circ} 2$. El error nominal de este instituto radica en que se trata de indemnizar los intereses individuales homogéneos (de todos los consumidores) y no al colectivo (que están más allá de la sumatoria de todos ellos).

${ }^{30}$ En este sentido, puede revisarse GONZÁLEZ GAZORLA (2017), pp. 200-201; LORENZINI BARRía (2015), p. 441.

31 Aguirrezabal Grünstein (2014), p. 10.
} 


\subsection{La dignidad de los consumidores como puerta de entrada al daño moral colectivo}

Alejándonos ya de una noción estrictamente subjetiva de daño moral ligada al dolor o sufrimiento, y considerando que la integridad física y psíquica no responderían al concepto de daño colectivo como una lesión a un interés grupal e indivisible, es necesario -por consiguiente- situar el ámbito de aplicación de este tipo de afectación sobre la base de una noción más objetiva, ya sea como lesión a un bien de la personalidad (en el ámbito colectivo) o como la afectación de la dignidad de la persona humana. ${ }^{32}$

Creo que la dignidad puede abrir paso a la reparación del daño moral colectivo en un sentido más puro, por tres razones. La primera, porque ella le da un carácter más objetivo al daño moral. Segundo, porque separa las afectaciones individuales que cada persona puede tener respecto del plano colectivo, y tercero porque, según la noción de dignidad humana que involucremos, ella es transversal y puede afectar no solo a una, sino muchas personas determinadas o indeterminadas, legitimando una acción eminentemente colectiva. Pero, ante todo, la pregunta que cabe formularse es: qué entendemos por dignidad.

\subsection{1 ¿Qué es la dignidad?}

Trataré aquí la dignidad en el contexto de las relaciones de consumo puesto que el término posee una textura abierta que permite extender las reflexiones a otros horizontes que escapan al objeto del presente trabajo.

En primer lugar, se debe hacer presente que la dignidad de los consumidores, como categoría normativa, se encuentra reconocida expresamente en tres hipótesis de la LPC. La primera, como un límite a los mecanismos de seguridad y vigilancia de los establecimientos comerciales (art. 15 LPC), la segunda como una circunstancia agravante de la conducta del proveedor (art. 24 LPC), y la tercera como un supuesto de la reparación del daño moral en los procedimientos de interés colectivo (art. $51 \mathrm{~N}^{\circ} 2 \mathrm{LPC}$ ).

En ninguna parte de la ley se la define, y es entendible que así sea porque se trata de un concepto complejo y evolutivo, en tanto expande progresivamente su ámbito de aplicación para proteger al ser humano. En este sentido, la doctrina ha dicho que:

La dignidad humana no es una simple declaración ética, sino que se trata de una norma jurídica que consagra un derecho fundamental a favor de la persona y por el cual se establece el mandato constitucional a todas las autoridades, e incluso particulares, de respetar y proteger la dignidad de todo individuo, entendida ésta -en su núcleo más esencial- como el interés inherente a toda persona, por el mero hecho de serlo, a ser tratada como tal y no como un objeto, a no ser humillada, degradada, envilecida o cosificada. ${ }^{33}$

\footnotetext{
32 Medeiros Bahia y Gomes Medeiros (2019), p. 41. En Chile, Marcelo Barrientos señala que la afectación de la dignidad de la persona habilita para demandar indemnización por daño moral superando la tesis la reduccionista del pretium doloris. En este sentido BARRIENTOS ZAMORANO (2008), p. 95.

${ }^{33}$ Pérez Fuentes (2018), pp. 118-119.
} 
A este respecto, resulta particularmente interesante como se ha construido el concepto de dignidad en el Derecho del consumo. ${ }^{34}$ En principio, existirían dos formas de abordarla. La primera, en un sentido amplio, como un derecho a que todo consumidor tiene en el aspecto social o externo, es decir en el trato que se le debe dar con ocasión de una relación de consumo por parte del proveedor. En general, se refiere a la completa relación que este último tiene con el consumidor en virtud del cual se le debe tratar y atender conforme a parámetros adecuados de respeto y consideración como persona. Aparentemente, el ordenamiento jurídico argentino habría seguido este camino al consagrar la protección de la dignidad del consumidor en el artículo 42 de su carta fundamental, el cual señala: "Los consumidores y usuarios de bienes y servicios tienen derecho, en la relación de consumo, a la protección de su salud, seguridad e intereses económicos; a una información adecuada y veraz; a la libertad de elección, y a condiciones de trato equitativo y digno".

La doctrina de aquel país ha hecho énfasis en el carácter social de la dignidad del consumidor, señalando que: “(...) la expresión 'trato equitativo y digno', se refiere a un aspecto social o externo, es decir al honor y al respeto que se le debe dar a una persona. La dignidad es un principio elemental y de carácter supraestatal". ${ }^{35}$

Por otra parte, la segunda postura sobre la noción de dignidad es más restringida, en tanto esencia del ser humano, y que para constituir una verdadera afectación se requiere de una vejación o humillación del consumidor, especialmente si se va a ejercer una acción indemnizatoria que repare el daño causado. ${ }^{36}$ No basta entonces que haya un aspecto social o externo afectado por el trato del proveedor, sino un daño de entidad mayor.

En Chile la jurisprudencia ha oscilado en uno y otro sentido de la dignidad cuando el consumidor ejerce una acción indemnizatoria. Algunos tribunales piensan que se requiere de

\footnotetext{
${ }^{34}$ Isler construye la dignidad del consumidor desde la noción de igualdad; principio y derecho reconocido a nivel constitucional que impide la discriminación arbitraria. Véase ISLER SOTO (2019), p. 212.

${ }^{35}$ IMBROGNO (2005), p. 3.

${ }^{36}$ En este sentido GONZÁlez CAZORLA (2019), p. 124.
} 
un acto vejatorio o humillante de la persona del consumidor, ${ }^{37}$ mientras que otros opinan que es suficiente un trato desconsiderado en el aspecto social. ${ }^{38}$

Ahora bien, en lo que tiene que ver con el daño moral colectivo y la hipótesis de dignidad que lo haría procedente, cabe preguntarse cuál de las dos nociones correspondería aplicar. Si adoptamos el primer sentido de dignidad tendríamos que llegar a la conclusión de que existe un bien colectivo e indivisible que permite gozar de un buen trato, en el aspecto externo, en las relaciones de consumo. En cambio, si es el segundo sentido el que adoptamos, se deben reconocer dos cosas: a) que existe un derecho colectivo, separado de las pretensiones individuales, y por tanto indivisible, a no ser humillado o envilecido y; b) que solo en caso de humillación o infracción grave de ese derecho, cabe reparar el daño moral en el plano colectivo.

Ya he mencionado lo dificultoso que resulta pensar en una afectación colectiva de la integridad física y psíquica de los consumidores, y las hipótesis de dignidad que acabo de describir no escapan a esa crítica, puesto que también resulta complejo imaginar cómo un proveedor puede provocar un daño en el aspecto social o externo a muchos consumidores, o humillarlos de tal forma que legitime una demanda colectiva.

Sin embargo, creo que hay una tercera categoría de dignidad que puede dar respuesta sin las dificultades teóricas de las dos primeras versiones. Para ello es necesario recurrir a un nivel más abstracto de dignidad que permita construir una hipótesis general de reparación sin la tesitura de tener que comprobar un mal trato o una humillación. En efecto, se trata de una noción que concibe a la dignidad como afectación de la calidad de vida de las personas.

En ese orden de ideas, el daño moral colectivo, como afectación a un interés grupal, se sitúa no como la mera insatisfacción de bienes colectivos, sino como un menoscabo del plan de vida de las personas, sus proyecciones y la calidad de la misma en un entorno masivo.

37 Jara con Administradora de Supermercados Hiper Limitada, (2016), considerando 7: "Que la defensa de Administradora de supermercados Híper Limitada, sin especificar la forma, contenido y lapso por el que se prolongó "el procedimiento de rigor", reconoce que, en definitiva, éste careció del presupuesto que la ley establece para permitir la detención de la consumidora demandante, esto es, la comisión de un delito flagrante, pretendiendo justificar su acción en 'un malentendido', pues "se comprobó que todos los productos adquiridos por la querellante, aparecían registrados en la boleta de compra"; de manera que la actora sin causa justificativa alguna fue sometida a un procedimiento contrario a derecho y que ha atentado en contra de su dignidad". $\mathcal{N} o$ se consigna con $\mathcal{N}$ o se consigna (2008), considerando $4^{\circ}$ : "Que, el mérito de los antecedentes allegados a los autos reseñados precedentemente, son elementos de juicio apreciados de conformidad a las reglas de la sana crítica, se logra tener por establecido que doña (...) el día 2 de agosto de 2007 alrededor de las 14:00 ingresó a la tienda Johnsons en la ciudad de Ovalle, y que al momento de retirarse sonó una alarma siendo alcanzada por un guardia, quien la obligó a ingresar a la tienda, que luego junto a otro guardia fue obligada a reingresar a la tienda, momentos en que nuevamente sonó el alarma, y que fue llamado Carabineros, siendo llevada por los guardias a un cuarto para ser revisada, para lo cual llamaron a una mujer para que la revisara, desnudada parcialmente y revisada, no encontrándose nada, y que al salir de la tienda nuevamente la alarma sonó, siendo revisada nuevamente en la Comisaría, para lo cual fue desnudada, sin encontrar nada. Que los hechos así descritos y establecidos, permiten colegir que la alarma se activó tres veces y que habiendo sido revisada la persona, no se le encontró ninguna especie lo que lleva a concluir que los procedimientos de seguridad de la tienda denunciada funcionaron defectuosamente, lo cual trajo como consecuencia que la dignidad de la denunciante se viera afectada" (énfasis añadido).

${ }^{38}$ Ribeiro con Sociedad Pacific Limitada (2007); Bruna con Moya (2009), considerando $6^{\circ}$. 
Es cierto que si el proveedor incumple sus obligaciones para con los consumidores estos verán mermadas sus expectativas al no contar con la prestación o bien que iba en su beneficio directo, pero ello se torna mucho más grave atendida las particularidades del mismo, como por ejemplo la publicidad falsa o engañosa, la introducción de productos defectuosos en el mercado o la prestación defectuosa de servicios a un número importante de personas, como el de agua potable, luz eléctrica, internet, etc. En estos casos no está solamente en juego el interés individual de los consumidores, sino que importa a todos que dichos hechos no se produzcan, ya que, al tener lugar estos, no solo frustran un derecho individual, sino que menoscaba la confianza, la calidad y el plan de vida que tienen las personas respecto de esos bienes o servicios.

Por ejemplo, y aunque se trata de un caso de responsabilidad civil extracontractual, hubo una demanda interpuesta por una comunidad de personas en contra del Fisco, la Municipalidad de Puente Alto y de una inmobiliaria por haber permitido la construcción de un conjunto habitacional aledaño a un ex vertedero que hasta entonces generaba malos olores y emanación de gases que afectaban la vida cotidiana de las personas que vivían cerca. El caso llegó hasta la Corte Suprema en donde fue discutido el daño moral sufrido por los demandantes (vecinos del sector) y la Corte se pronunció con el siguiente tenor:

Que, en cuanto al daño moral o extrapatrimonial, sólo sustituyéndose intelectualmente esta Corte en la persona de los demandantes puede presumirse $-\mathrm{y}$ las presunciones son un medio de prueba- la existencia de un evidente perjuicio de índole psicológico derivado del hecho de vivir al lado de lo que fue el vertedero La Cañamera, con malos olores en verano, con emanaciones de gas por las alcantarillas, existiendo en la actualidad chimeneas construidas para evacuar los gases (..... ${ }^{39}$

Aunque la Corte Suprema haya hecho una valoración del daño como afectación psicológica derivada de los hechos, lo cierto es que no puede desconocerse que una lesión como la mencionada no solo interesa en el plano individual, sino que constituye una vulneración de la dignidad humana, bien jurídico que no solo ejerce personalmente, sino que puede tener lugar en un plano abstracto, en comunidad, por lo que, al margen del sufrimiento especifico que cada uno de los vecinos haya padecido, la vida, convivencia y entorno social se vio profundamente mermada por las condiciones sanitarias del sector contaminado.

\section{3 ¿Cómo se produce la afectación a un interés grupal?}

De acuerdo con el caso citado anteriormente, considero que para que se produzca la afectación a un interés grupal en el ámbito del consumo, este debe mermar la calidad de vida de los consumidores o usuarios. En otras palabras, su plan o condiciones de vida, salud y entorno en que el habitualmente desarrolla sus actividades son menoscabados, es decir, ya no puede continuar con su vida como lo hacía antes. Por eso, más allá del dolor o sufrimiento sicológico del que se padezca, serán las condiciones de vida antes y después de la infracción del proveedor las que determinarán el detrimento provocado, y es en ese sentido que la

${ }^{39}$ Lizana y otros con Municipalidad de Puente Alto y otros (2013), considerando $17^{\circ}$. 
dignidad se transforma en un bien jurídico que otorga al daño moral colectivo un aspecto más objetivo, sin calificaciones individuales, sino de la constatación fáctica entre dos momentos distintos.

Por esto, la dignidad de la persona - proyectada como un derecho de la personalidadabre un espacio mucho más amplio que la afectación sicológica o física del individuo, porque, precisamente, ella abarca un amplio y más profundo espectro del ser humano, de manera que la afectación de este se configura de una forma más amplia comparado con los casos individuales.

\section{SENTENGIAS PRONUNGIADAS SOBRE DAÑO MORAL GOLEGTIVO EN CHILE}

Antes de finalizar este trabajo, conviene hacer referencia a dos sentencias que se han pronunciado dando lugar al daño moral en procedimientos de interés colectivo contra el texto prohibitivo expreso de la LPG (antiguo artículo $51 \mathrm{~N}^{\circ}$ 2), antes de la reforma de la ley 21.081..$^{40}$ La primera de ellas es del $1^{\circ}$ Juzgado de Letras de Osorno, de fecha 31 de diciembre de 2014, ${ }^{41}$ y la segunda del $13^{\circ}$ Juzgado Civil de Santiago, de fecha 13 de junio de $2017 .{ }^{42}$

La sentencia del tribunal de Osorno se dicta con ocasión de una denuncia presentada por el Servicio Nacional del Consumidor (Sernac), debido a la infracción del proveedor demandado respecto las bases de un concurso para ganar un automóvil, avaluado en más de 23 millones de pesos. De acuerdo a la sentencia de primera instancia las bases del premio no eran claras puesto que el horario del sorteo no quedaba del todo claro como tampoco el tiempo límite que los consumidores tenían para participar del mismo depositando sus copones en el respectivo buzón.

El concurso se llevaría a cabo dentro de un recinto que sirve de casino y dentro del cual los consumidores podían adquirir los cupones para participar del sorteo, sin embargo, se detectaron algunas anomalías, por ejemplo que los buzones se cerraron 4 horas antes del tiempo límite, como también la sobreventa de entradas al recinto que solo era para 1500 personas, por lo que cientos de consumidores no pudieron ingresar al mismo quedando afuera de las instalaciones, produciéndose problemas de seguridad tanto afuera como dentro del establecimiento, debiendo llegar Carabineros a controlar el orden, y generándose detenciones y lesionados, por lo que tuvo que llegar también la ambulancia para asistirlos.

El sorteo se llevo a cabo pasada la medianoche del 31 de enero de 2011 con algunas irregularidades que los consumidores acusaron en ese entonces, básicamente la infracción de los requisitos para ser ganador, que es la de reclamar el premio dentro de 60 segundos desde que la persona es llamada a viva voz por el locutor. La persona ganadora subió al escenario a recibir el premio después del tiempo descrito en las bases.

\footnotetext{
${ }^{40}$ Puede revisarse un detallado análisis de estas dos sentencias en Reveco Soto (2019), pp. 75-100.

41 Servicio Nacional del Consumidor con Latin Gaming Osorno (2014).

42 Servicio Nacional del Consumidor con Feria Ticket S.A. y otro (2017).
} 
Ante estos hechos el Juzgado de Letras Osorno constató la infracción al artículo $3^{\circ}$ letra b), el derecho a una información veraz y oportuna; art. $3^{\circ}$ letra d) derecho a la seguridad en el consumo; artículo 12, al infringirse los términos y condiciones y; artículo 23, todos de la LPC. Asimismo, ordenó pagar las respectivas multas por las infracciones efectuadas, pero más importante, ordenó reparar el daño moral de los consumidores por una cantidad de 100 mil pesos de acuerdo a lo solicitado por el Sernac, en defensa del interés colectivo, y además se ordena reparar el daño moral causado a cada uno de los demandantes que se hicieron parte, que eran 97, por la suma de 100 mil pesos por cada uno.

Es relevante destacar que el tribunal consideró que se produjo un daño moral a cada uno de los demandantes, en cuanto este estaba constituido por "las incomodidades, desagrados, frustraciones, incomprensiones, riesgos, descortesías y decepciones generadas por las infracciones cometidas (...)". ${ }^{43}$

El asunto se elevó a la Corte de Apelaciones de Valdivia y esta revocó lo resuelto por el tribunal de primera instancia en lo relativo al daño moral de los consumidores, solicitado en virtud del interés colectivo, por expresa exclusión (en ese tiempo) del artículo 51 No 2 LPC. Sin embargo, dio lugar a la reparación de este daño a los 97 demandantes, pero rebajando la suma de 100 mil pesos a la cantidad de 3 UTM, según se lee a continuación:

La acción fue interpuesta por un número determinado de consumidores, los que se individualizaron, quedando establecida su calidad de asistentes al evento y quienes demostraron tener una pretensión concreta, asistiéndoles el derecho a demandar indemnizaciones, entre las cuales se comprende aquella por daño moral, al encontrarse acreditada su plausibilidad para demandar civilmente establecida las infracciones en que incurrió la demandada, como asimismo las molestias, frustraciones, y demás afecciones personales indicadas en la sentencia recurrida, a lo cual debe agregarse lo razonado en el considerando décimo séptimo de este fallo de alzada, se estima adecuado fijar una indemnización por este concepto, ascendente a 3 Unidades Tributarias Mensuales para cada actor civil. ${ }^{44}$

Como se puede apreciar, la Corte de Apelaciones de Valdivia dio lugar a la reparación del daño moral sufrido por los 97 consumidores que se hicieron parte a la denuncia efectuada por el Sernac. Sin embargo, la cuestión crítica emerge desde que no era necesario recurrir a una noción subjetiva de daño moral, como molestias o frustraciones, puesto que no fundamenta cómo aquello constituye una vulneración a un bien colectivo. En su lugar, habría sido más conveniente hablar de afectación de la dignidad de los consumidores como bien abstracto, especificando cómo ello constituye una afectación de ese bien jurídico cuyo goce pertenece a todos los consumidores lesionados. Cabe mencionar además, que el fallo de segunda instancia fue recurrido para ante la Corte Suprema a través de un recurso de casación en el fondo por infracción del artículo $51 \mathrm{~N}^{\circ} 2 \mathrm{LPC}$, que excluye la reparación del daño moral, pero el máximo tribunal lo rechazó por manifiesta falta de fundamento arguyendo que el demandado no alegó esta circunstancia en la contestación de la demanda,

43 Servicio Nacional del Consumidor con Latin Gaming Osorno S.A. (2014), considerando $20^{\circ}$.

${ }^{44}$ Servicio Nacional del Consumidor con Latin Gaming Osorno S.A. (2015), considerando $19^{\circ}$. 
por lo que la casación no puede servir de mecanismo para la introducción de nuevas alegaciones no realizadas en las instancias respectivas. ${ }^{45}$

La segunda sentencia, pronunciada por el $13^{\circ}$ Juzgado Civil de Santiago, tiene lugar ante demanda colectiva presentada por el Sernac en contra de una empresa intermediaria, vendedora de entradas, como aquella que debía dar cumplimiento a un espectáculo musical que finalmente fue cancelado, alegándose la infracción a los artículos, 3 letra b) y e), artículo 12 y 23, todos de la LPG, por el incumplimiento tanto de la prestación contratada como de la devolución del dinero correspondiente al valor de entrada al mencionado recital.

Según la sentencia de primera instancia, ambas empresas fueron condenadas a pagar las respectivas multas por las infracciones cometidas y, lo novedoso, es que la proveedora de tickets fue condenada a pagar la suma de $\$ 50.000$ por cada uno de los 4.315 consumidores que compraron las entradas para asistir al concierto, mientras que la empresa a cargo de proveer el servicio fue condenada a pagar $\$ 30.000$ por cada uno de los 4.315 consumidores que compraron las entradas, en ambos casos, más reajustes e intereses legales, ${ }^{46}$ a título de daño moral. Apelado el fallo de primer grado, fue confirmado sin más por la Corte de Apelaciones de Santiago.

El Sernac interpone recurso de casación de casación en el fondo solicitando que se invalide la sentencia de autos, puesto que no hubo una correcta valoración de los montos correspondientes al valor de las entradas para el concierto, que debía compensar uno de los demandados. Sin embargo, dicha impugnación fue rechazada por manifiesta falta de fundamento, al querer cuestionar la ponderación de los hechos efectuada por los jueces del grado, siendo ello inamovible para la Corte Suprema. ${ }^{47}$

\section{GONGLUSIONES}

Durante el desarrollo del trabajo hemos detectado algunas ideas claves que sirven de base para una mejor comprensión de los intereses supraindividuales, el daño moral colectivo y la regulación que hace el legislador chileno mediante la Ley 21.081, reformando la LPC. En efecto, a modo de síntesis de los temas abordados, me referiré a algunas ideas que cuentan también como conclusiones:

1. Para comprender correctamente el denominado daño moral colectivo se advierte la necesidad de establecer las bases conceptuales relativas a los distintos intereses en juego. En particular, los intereses individuales de los intereses supraindividuales, como el colectivo y el difuso.

2. El daño moral puede tener una aplicación diferenciada según el tipo de interés involucrado. Cuando se trata de un interés individual suelen aplicarse las teorías tradicionales para explicarlo, sin embargo, esas mismas teorías no responden en forma completa y suficiente cuando se ven confrontadas a intereses supraindividuales.

\footnotetext{
45 Servicio Nacional del Consumidor con Latin Gaming Osorno S.A., (2016).

46 Servicio Nacional del Consumidor con Feria Ticket S.A. y otro, (2017).

47 Servicio Nacional del Consumidor con Feria Ticket S.A. y otro, (2018).
} 
3. El daño moral colectivo no puede ser explicado como el dolor o molestias sufridas por muchas personas, puesto que no se trata de la suma de afectaciones individuales. De este modo, se advierte que, para referirse a este tipo de lesión en un sentido más técnico, no pueden atenderse a las repercusiones particulares padecidos por los miembros de la colectividad, porque se trata de un daño independiente y autónomo de aquel que sufren los sujetos en su esfera personal.

4. La ley 21.081 ha introducido una forma particular de daño moral en el contexto de las acciones colectivas en el artículo $51 \mathrm{~N}^{\circ} 2$ LPC. Se han tomado como hipótesis de procedencia la integridad física, psíquica o la dignidad de los consumidores. Sobre los dos primeros bienes jurídicos, el legislador pareciera extrapolar las tradicionales doctrina y jurisprudencia sobre el daño moral como una aflicción física, sicológica o emocional, y no parece advertir la diferencia entre un interés individual y uno colectivo.

5. Sin embargo, en cuanto a la dignidad de los consumidores, pueden erigirse las bases conceptuales para llegar a una noción de daño moral colectivo más genuino. Para ello, es necesario arribar a la idea de dignidad como afectación de un bien de la personalidad en un ámbito colectivo o, al menos, como la lesión a las condiciones o calidad de vida de las personas. De esta manera, no hay inconveniente en la particular sensación de desagrado que genera la conducta del proveedor, sino que se sustenta por sí misma una lesión autónoma que reclama indemnización.

6. El daño moral colectivo, entonces, es la afectación a un interés grupal. Dicha afectación se materializa con el menoscabo a la calidad de vida de los consumidores o de su dignidad. No se requiere, por tanto, que exista sufrimiento de las personas, ni que exista una lesión específica de su integridad personal, sino que basta un menoscabo o alteración en sus condiciones de vida causada por la conducta del proveedor.

7. El daño moral colectivo tiene lugar cuando los consumidores son determinados o determinables, puesto que este elemento (determinación) no solo sirve para mantener la identidad de la víctima, es decir de las personas que componen el grupo lesionado, sino que también es un insumo para responder a la certidumbre del daño, propio de la responsabilidad civil. En otras palabras, no es posible extender la reparación de este daño a personas indeterminadas porque no es posible atribuir el efecto dañoso a ninguna persona, menos a un grupo cuyos miembros son desconocidos.

8. En el caso que se considere que el cy pres ofluid recovery sea una herramienta útil para compensar a grupos de consumidores indeterminados, se deben abandonar los principios de la responsabilidad civil y arribar a un nuevo paradigma, puesto que no es posible satisfacer los requisitos de ella sin desatender que, en lugar de una efectiva reparación, se trata de disuadir o castigar al proveedor demandado. Además, el artículo 11 bis LPG no daría un margen discrecional al juez para determinar una alternativa compensatoria tan cercana como sea posible.

9. Por último, y hasta donde mis noticias llegan, hay dos sentencias que se pronuncian favorablemente respecto del daño moral alegado en acciones colectivas de consumidores en Chile. En ambas, pareciera primar la tesis tradicional del daño moral como la afectación sicológica, emocional, molestias, desagrado o frustración provocada por el proveedor con su 
incumplimiento. Sin embargo, para evitar confusiones infructuosas, creo que se debe trabajar en las interpretaciones actuales para tener decisiones más fundadas y menos elucubradas en el futuro. 


\section{BIBLIOGRAFÍA GITADA}

Acosta Estévez, José (1995). Tutela procesal de los consumidores (Barcelona: Bosch).

AEdo BARrena, Cristián Eduardo (2019). El concepto de daño moral. Zonas problemáticas, en CÉsPedes MuÑoz, Carlos (director) Estudios de Derecho Privado en memoria del profesor Nelson Vera Moraga (Santiago: Thomson Reuters), pp. 149-174.

Aguirrezabal Grünstein, Maite (2014). Defensa de los consumidores y acceso a la justicia. Un análisis del procedimiento colectivo en la legislación chilena (Santiago: Thomson Reuters).

Alessandri RoDRíGuez, Arturo (1943) De la responsabilidad extracontractual en el Derecho Civil Chileno, (Santiago, Imprenta Universitaria).

Barrientos Camus, Francisca (2017). "Proyecto de ley de fortalecimiento del Sernac y las Asociaciones de Consumidores", en Boletín Especial ADECO, Universidad Diego Portales, pp. 20-24.

BARRIENTOS ZAMORANO, Marcelo (2008). "Del daño moral al daño extrapatrimonial: la superación del pretium doloris", Revista Chilena de Derecho, Vol. 35, No 1, pp. 85-106.

BARros Bourie, Enrique (2006). Tratado de responsabilidad extracontractual (Santiago: Editorial Jurídica de Chile).

Cavalieri Filho, Sergio (2012). Programa de responsabilidad civil (Sao Paulo: Atlas).

Contardo GonzÁlez, Juan Ignacio y CORTEz LóPez, Hernán Felipe (2019). Cuantificación del daño moral de los consumidores. Tendencias y sentencias (Santiago: DER Ediciones).

DE LA MAZA GAZMURI, Íñigo (2020). "La indemnización del daño en las acciones colectivas masivas: ¿Una promesa incumplida?, en ElORRIAGA DE BONIS, Fabián (editor), Estudios de Derecho Civil XV. XVII Jornadas Nacionales de Derecho Civil (Santiago, Thomson Reuters) pp. 783-798.

Diez-PiCazo, Luis (1999) Derecho de Daños (Madrid: Civitas).

Domínguez Hidalgo, Carmen (2000). El daño moral, Santiago: Editorial Jurídica de Chile, tomos I y II.

Domínguez Hidalgo, Carmen (2019). "Los derechos de la personalidad y el principio de reparación integral del daño", en Domínguez HidalgO, Carmen (edit.) El principio de reparación integral en sus contornos actuales. Una revisión desde el derecho chileno, latinoamericano y europeo (Santiago: Thomson Reuters), pp. 83-99.

GIDI, Antonio (2003). "Derechos difusos, colectivos e individuales homogéneos", en GIDI, Antonio y FERRER MAC GREGOR, Eduardo (coords.) La tutela de los derechos difusos, colectivos e individuales homogéneos. Hacia un código modelo para Iberoamérica (México, Porrúa).

González Cazorla, Fabián (2017). "Delimitación del daño moral a través de consideraciones de justicia distributiva", Revista de Derecho de la Universidad de Concepción, No 242, pp. 191-220. 
GonzÁlez Cazorla, Fabián (2019). Daño moral en el Derecho del consumidor (Santiago: DER Ediciones).

HERnÁNDEZ PAUlSEN, Gabriel (2018). "Colusión y responsabilidad civil por daño colectivo a los consumidores", Revista Chilena de Derecho Privado, No 30, pp. 87-126.

Hernández Paulsen, Gabriel y Tapia RodríGuez, Mauricio (2019). Colusión y daño a los consumidores (Santiago: Thomson Reuters).

ImBROGNO, Andrea (2005). "Derecho del consumidor: La obligación de un trato digno y equitativo", Cartapacio de Derecho: Revista virtual de la Facultad de Derecho - Unicen, Vol. 8, pp. 1-9.

IsLer Soto, Erika (2019). Derecho del Consumo. Nociones fundamentales (Valencia: Tirant lo Blanch).

LORENZINI BARRÍA, Jaime (2015). "Los daños morales colectivos en las relaciones de consumo", en VIDAl Olivares, Álvaro (et al.) Estudios de Derecho Civil X. Fornadas Nacionales de Derecho Civil. Valparaíso, 2014, (Santiago: Thomson Reuters), pp. 433-452.

Martin-Casals, Miquel, Ribot, Jordi y Solé, Joseph (2003). "El daño moral”, en CÁmara, Sergio (coord.), Derecho Privado Europeo, (Madrid: Colex).

Medeiros Bahia, Carolina y Gomes Medeiros, Heloísa (2019). "Daño moral colectivo en las relaciones de consumo: caracterización, comparación entre el sistema brasileño y colombiano y la visión del tribunal Superior de Justicia en Brasil", Opinión furídica, $\mathrm{N}^{\mathrm{o}}$ 18 (36), pp. 37-55.

MOLINARI VALDÉS, Aldo (2018). "Improcedencia del daño moral como categoría de afectación al interés colectivo frente al reconocimiento del daño punitivo", en Bahamondes, Claudia; Etcheverry, Leonor y Pizarro, Carlos (editores), Estudios de Derecho Civil XIII. Fornadas Nacionales de Derecho Civil, Pucón 2017, (Santiago, Thomson Reuters), pp. 515-531.

Munita Marambio, Renzo (2019) "Daño moral y su cuestionable tratamiento desde la órbita de una acción colectiva o difusa (comentarios a la ley $\mathrm{N}^{\mathrm{o}} 21.081$ que modifica la ley $\mathrm{N}^{\mathrm{0}}$ 19.496, sobre protección de los derechos de los consumidores", Actualidad Jurídica, $\mathrm{N}^{\mathrm{o}} 39$, pp. 207-232.

Ovalle Favela, José (2013). "Las acciones colectivas", en GinebRA, Xavier (coord.) Las acciones colectivas en el Derecho Mexicano (México D.F., Tirant lo Blanch).

PÉREz FuenTES, Gisela María (2018). "Responsabilidad por daños a la persona: daño moral" en Pérez Fuentes, Gisela María (coord.) Temas actuales de responsabilidad civil (Ciudad de México, Tirant lo Blanch) pp. 99-149.

Pizarro Wilson, Carlos (2013). "Obligaciones y Responsabilidad Civil", Revista Chilena de Derecho Privado, N 20, pp. 217-223.

Redish, Martin H; Julian, Peter y Zyontz, Samantha (2010). "Cy pres relief and the pathologies of the modern class action: A normative and empirical analysis", Florida Law Review, Vol. 62, Num. 3, pp. 617-666. 
Reveco Soto, Eduardo (2019). "Comentario a dos fallos erráticos que han estimado procedente la indemnización del daño moral en el marco de acciones colectivas. ¿Una antesala de su estandarización, quántum y determinación de los "montos mínimos comunes" indemnizables mediante la Ley No 21.081", en Revista de Derecho y Consumo, $\mathrm{N}^{\mathrm{o}}$ 3, pp. 75-100.

RoDríGuEz Diez, Javier Esteban y ZAVALA ACHuRRA, María Elisa (2019). "Restitución e indemnización a sujetos indeterminados, cy-près y acciones de clase", Estudios SocioJurídicos, $\mathrm{N}^{\mathrm{o}} 21$, (1) pp. 151-176.

SÁEnZ, Luis R.J. (2014). "El daño moral en el Derecho del consumo", en RiTTO, Graciela y JaLiL, Julián (compiladores) El daño moral en la Ley de Defensa del Consumidor (Buenos Aires, Editorial de la Universidad de Ciencias Empresariales y Sociales).

TolosA, Pamela (2017). "Acciones de clase, "microdaños" a los consumidores y fliud recovery: alternativas institucionales y costos sociales", The Latin American and Iberian Journal of Law and Economics, Vol. 3 (1) pp. 77-98.

ZaVAla DE GonZÁLEZ, Matilde (1999). "Los daños morales colectivos", Lecciones y Ensayos, $\mathrm{N}^{\mathrm{o}} 72 / 73 / 74$, pp. 145-159. 


\section{NORMAS CITADAS}

\section{Argentina:}

Constitución de la Nación Argentina de 3 de enero de 1995.

Ley N 24.240 de 13 de octubre de 1993, sobre Normas de Protección y Defensa de los Consumidores. Autoridad de aplicación. Procedimiento y Sanciones. Disposiciones Finales.

\section{Brasil:}

Ley $\mathrm{N}^{\mathrm{o}} 7.347$ de 24 de julio de 1985.

Ley $\mathrm{N}^{\mathrm{o}} 8.078$ de 11 de septiembre de 1990, sobre protección del consumidor y otras disposiciones.

\section{Chile:}

Código Civil de la República de Chile de 14 de diciembre de 1855.

Código de Procedimiento Civil de la República de Chile de 30 de agosto de 1902.

Ley $\mathrm{N}^{\circ} 19.496$ de 7 de marzo de 1997, que establece normas sobre protección de los derechos de los consumidores.

Ley $\mathrm{N}^{\mathrm{o}} 21.081$ de 13 de septiembre de 2018, que modifica la Ley 19.496, sobre protección de los derechos de los consumidores.

\section{Colombia:}

Constitución Política de la Republica de Colombia de 4 de julio de 1991.

Ley $\mathrm{N}^{\mathrm{o}}$ 472/1998 de 6 de agosto de 1998.

Ley $\mathrm{N}^{\circ} 1480 / 2011$ de 12 de octubre de 2011, por medio de la cual se expide el Estatuto del Consumidor y se dictan otras disposiciones. 


\section{JURISPRUDENGIA GITADA}

\section{Chile:}

Águila y otros con Comercializadora del Sur Seis Limitada (2009): Corte de Apelaciones de Valdivia, 20 de diciembre de 2009, Rol 264-2009, Thomson Reuters CL/JUR/5504/2009.

Bruna con Moya (2009), Corte de Apelaciones de Antofagasta, 24 de febrero de 2009, Rol 1902008.

Cortez y otros con Cooperativa de Servicios Educacionales Windsor School Ltda. (2010): Corte de Apelaciones de Valdivia, 20 de abril de 2010, Rol N 52-2010, Thomson Reuters CL/JUR/2645/2010.

Cuevas con Distribuidoras de Industrias Nacionales S.A. (2011): Corte de Apelaciones de Santiago, 8 de noviembre de 2011, Rol N 1910-2011, Thomson Reuters CL/JUR/8609/2011.

Fredes con Multitienda Corona S.A. (2013): Corte de Apelaciones de Concepción, 29 de mayo de 2013, Rol 359-2012, Thomson Reuters CL/JUR/1157/2013.

Gutiérrez y otros con Rendic Hermanos S.A. (2009): Corte de Apelaciones de Antofagasta, 11 de septiembre de 2009, Rol 86-2009, Thomson Reuters CL/JUR/3939/2009.

Huentemil y otros con Agro Inversiones (2007): Corte de Apelaciones de Concepción, 12 de diciembre de 2007, Rol N 423-2007, Thomson Reuters CL/JUR/5598/2007.

Fara con Administradora de Supermercados Hiper Limitada (2016): Corte de Apelaciones de Concepción, 21 de octubre de 2016, Rol 275-2016, Thomson Reuters CL/JUR/8055/2016

Lizana y otros con Municipalidad de Puente Alto y otros (2013): Corte Suprema, 7 de mayo de 2013, Rol 10.156-2010, Thomson Reuters CL/JUR/974/2013.

Muñoz con Administradora de Supermercado Express Limitada (2012): Corte de Apelaciones de San Miguel, 16 de abril de 2012, Rol 302-2012, Thomson Reuters CL/JUR/818/2012.

No se consigna con No se consigna (2008): Corte de Apelaciones de La Serena, 28 de noviembre de 2008, Rol 176-2008, Thomson Reuters CL/JUR/4202/200.

Quezada con Colmenares Werner Limitada (2016): Corte de Apelaciones de San Miguel, 4 de mayo de 2016, Rol No 84-2016, Thomson Reuters CL/JUR/2932/2016.

Quezada con Colmenares Werner Limitada (2016): Corte Suprema, 27 de diciembre de 2016, Rol No 33.990-2016, Thomson Reuters CL/JUR/8712/2016.

Ribeiro con Sociedad Pacific Limitada (2007), Corte de Apelaciones de La Serena, 7 de diciembre de 2007, Rol 28-2007.

Servicio Nacional del Consumidor con Latin Gaming Osorno S.A., (2014): $1^{\circ}$ Juzgado de Letras de Osorno, 31 de diciembre de 2014, Rol 192-2012.

Servicio Nacional del Consumidor con Feria Ticket S.A. y otro (2017): $13^{\circ}$ Juzgado Civil de Santiago, 13 de junio de 2017, Rol 9870-2013. 
Servicio Nacional del Consumidor con Latin Gaming Osorno S.A. (2015): Corte de Apelaciones de Valdivia, 12 de mayo de 2015, Rol 185-2015.

Servicio Nacional del Consumidor con Feria Ticket S.A. y otro (2018): Corte Suprema, 6 de diciembre de 2018, Rol 16.355-2018, Thomson Reuters CL/JUR/6797/2018. 